\title{
Auto Components Industry Deepening the Supply Chain Management in ASEAN.
}

\author{
${ }^{1}$ Dr (Mrs) Muneer Sultana, ${ }^{2}$ Khairul Amilin Ibrahim. \\ ${ }^{1,2}$.International College of Automotive, DRB-HICOM, Automotive Complex, Peramujaya, Industrial Area, \\ Pekan, Pahang. Malaysia.
}

\begin{abstract}
:
Aims: Supply chain management (SCM) in automotive is the organization of the movement of auto products. It comprises the undertaking and storage of raw materials, work-in-process list, and completed automotive products from idea of foundation to idea of consumption. Interrelated or added webs, networks and node auto businesses are elaborate in the establishment of auto products and services prerequisite by end consumers in a supply chain. Automotive industry is a representation of mechanical genius by human generous. Being one of the wildest mounting segments in the domain its energetic development stages are described by environment of competition, product life cycle and customer request. Global manufacture webs show a significant part in East Asian financial prudence. Organizations in a supply chain organise and segment the as $\mathrm{s}$ s $t$ a $\mathrm{n}$ ces through market place instruments, ag re ements, and corporation preparations, which prime to the snowballing competence of all associates. In today's hard-ing economy, the rivalry amongst great companies has long been prolonged to struggle among troupes in supply chains. Completely Built Unit (CBU) is a car which is not creations or even gathered in the country deal. Such cars are trade in from the country of engineering and vended in the country of introduction. These cars don't necessitate any engineering plant as it is directly sold in the target country's marketplace. Auto engineering includes hundreds of portions from many dealers; supply chain management is a serious part in processes organization of the trade and a conclusive issue for the accomplishment or existence of the auto manufacturers. In such a case a study has been conducted to know the completely built units of automotive increasing through supply chain in ASEAN.
\end{abstract}

Place and Duration of the Study: ASEAN brief data on automotive supply chain management and study is from 2010 to 2013.

Methodology: The study is equipped grounded on primary and secondary sources. The primary source has composed through oral interview from stalwarts of automotive industry. The secondary data is collected from the reports of international conference of automotive industry and all existing literature has collected also from internet automotive websites, auto business magazines, e-auto journals etc.

Results: Finding out the research depicts that total quantity of passenger and commercial vehicles have diminished due to snowballing rivalry among ASEAN auto portions supply chain management. Finally suggestions have been framed and conclusions have been drawn for the study.

Conclusion: Automotive supply chains requirement fact-based aptitude to envisage which forthcoming situations are most likely to transpire - and the elasticity to get transposed previously they do. Now additional than continuously, shrewd successes.

Key Words: Auto, components, Supply Chain Management, Conference, ASEAN, Automotive Industries. Type: Research Paper.

\section{Introduction}

Conveyance is unique of the further most indispensable financial properties in the contemporary domain. A proficient method of conveyance safeguards the movement of individuals and product distribution could be accompanied in a harmless and suitable method. To encounter this prerequisite, numerous categories and representations of automobiles were created by automotive corporations to accomplish the requirements of customers specifically in the perspective of passenger automobiles. With promptly fluctuating and under very modest situations, the strategy, enlargement and marketing of new auto products with inventive and advanced structures are indispensable for any corporation's existence. For innovative auto product progress to be operative, an organized method to the considerate of consumer desires is essential. These desires should then be decisively devoted to forthcoming seller's auto product developments. Within the automotive production the corresponding and organization of forthcoming composite sub-assemblies and occupied arrangements requirements to be achieved prudently amongst providers and supplier-customer to safeguard development 
completion. The inventive auto product growth and auto manufacture procedure prerequisites considerate of endlessly fluctuating consumer requirements and desires. The Association of Southeast Asian Nations is a geopolitical and financial group of ten nations situated in Southeast Asia, which was formed on 8 August 1967 by Indonesia, Malaysia, the Philippines, Singapore and Thailand. Since then, association has lengthened to include Brunei, Burma (Myanmar), Cambodia, Laos, and Vietnam. Its purposes consist of hastening economic growth, social progress, and ethnic progress amongst its associates, fortification of provincial amity and firmness, and chances for associate nations to deliberate variances quietly. Automotive Production "all those corporations and events elaborate in the production of motorised automobiles, as well as further most machineries, such as appliances and figures, but exclusive of wearies, sequences, and petroleum. The manufacturing's foremost goods are customer vehicles and bright automobiles, counting pickups, forefronts, and entertainment effectiveness automobiles. Marketable automobiles (i.e., distribution automobiles and great vehicle vans, frequently called semis), however significant to the trade, are subordinate". Supply chain management (SCM) in automotive is the organization of the movement of auto products. It comprises the undertaking and loading of raw materials, work-in-process record, and complete auto products from idea of basis to opinion of consumption. Interrelated or interspersed webs, networks and node auto businesses are elaborate in the establishment of auto products and services essential by end consumers in a supply chain. Supply chain management has been well-defined as the "strategy, forecasting, accomplishment, regulator, and observing of supply chain events with the impartial of generating clear worth, structure a modest substructure, leveraging international logistics, coordinating supply with mandate and assessing presentation comprehensively." Automotive production is a sign of mechanical genius by social generous. Certainty one of the wildest mounting segments in the domain its vigorous development stages are clarified by countryside of rivalry, product life cycle and customer request. Global manufacture webs show a significant part in East Asian economies .Companies in a supply chain organise and segment the assistances through market mechanisms, a greements, and firm preparations, which principal to the snowballing effectiveness of all associates. In today's treacherous economy, the rivalry among great establishments as long been protracted to the struggle midst companies in supply chains. Completely Built Unit (CBU) is a car which is not auto productions or smooth accumulated in the nation transaction. Such cars are introduced from the nation of industrial and traded in the nation of introduction. These cars don't need any industrial plant as it is straight traded in the goal nation's market place. Auto industrial comprises hundreds of fragments from many providers; supply chain management is a serious part in processesassociationofthebusinessandaconclusivefeaturefortheachievementorexistence of the auto manufacturers. In such a case a study has been conducted to know the completely built units of automotive increasing through supply chain in ASEAN.

\subsection{Need and Significance of the Study:-}

The manufacture and transactions amount in the motorised segment is measured an imperative orientation to financial development and presentation in any specific nation. The automotive manufacturing is requiring a sturdy multiplier consequence on the development of a nation and henceforth is accomplished of existence the chauffeur of financial development. It shows a foremost momentous part in mounting transportation segment in unique indicator and support business segment on the additional to produce quicker and in that way products substantial occupation chances. Also as ASEAN republics are opening the terrestrial edge for occupation and emerging global high way associations, the influence of automotive segment in snowballing distributes and introductions will be suggestively high. As automotive business is fetching additional and extra consistent, the equal of rivalry is snowballing and manufacture improper of furthermost of auto-giant corporations are existence cleaned from the industrialized nations to emerging nations to yield the benefit of low price of auto manufacture. It is essential and significant to study about automotive industry in serious efforts to grab these opportunities in supply chain of auto parts which include many Asian countries such as Thailand, China, India and Indonesia.

1.2. Objectives of the Study: -

(i). To Examine the Quantity of auto parts of Commercial and Passenger Vehicles through supply chain in ASEAN.

(ii) To Study the Import of Completely Built Up (CBU) auto parts through supply Chain in ASEAN.

1.3. Scope of the Study: The study covers the ASEAN countries to the extent of automotive industries, with special emphasis on knowledge of automotive of only ASEAN countries. 
1.4. Limitations of the Study: - The study of auto components industry deepening the supply chain management in ASEAN is prepared based on secondary data and the secondary data was limited to the extent of the ASEAN automotive industry only.

\section{PREVIOUS STUDIES.}

2.1. According to Bartlett etal. (2007) ${ }^{1}$ stated that, within the segmental stream web, discernibility essentialtorealizeevidencedistributionwithrespecttomanufactureforecastingandlogistics-relatedfacts, aswell as progress the segmental amount presentation, can be realized if providers and producers effort on combined creativities.

2.2. According to Reichhart and Holweg, $(2007)^{2}$ opined that, adjacent localities of the segment dealers and the automakers are cooperative for segmental amount, which may be why seller commons are general structures used to attain Just In Time (JIT) supply in the automotive production.

2.3. Sandberg $(2007)^{3}$ indicated that, top organization participation also shows a significant part in attaining high-performance logistics association among the component provider and the producer.

2.4. Kurylko, (2007) ${ }^{4}$ showed that, Audi underway a package called the "Audi modular longitudinal plat formtechnology"onitsA5/S5 coupe, substituting to a segmental construction that will allow greatest of its product shapes to portion foremost modules. Complete its segmental method, Audihasestablishedcomponentsfordearerworkings,countingboilerandairingandvitalworkingsoftheform,determina tiontrain,andpostponement.

2.5. Erevellesand Stevenson, $(2006)^{5}$ revealed that, auto makers interchange extra near segmental gathering; the guidelines and observes of the supply web are fluctuating. The composite product arrangement and supplier web mark sit stimulating to put on modularity and association within the upstream supply chain.Establishmentsareprogressivelyforcedtocontractwithbettercomplicationsinthe world-widesupply chain, in relations of together the quantity of suppliers and fluctuating appearances.

2.6. Doranetal., (2007) ${ }^{6}$ stated that, A distinctive automaker obligation behaviour trade with roughly200300suppliers, buttheSmartcarhas

(called"systempartners")thatdeliverscomponents,countingwholeconsole only25segmentsuppliers

structures, figureconstruction, deceleratingregulatorschemes, andseating components.

2.7. Brazil,

Kotabeetal.,(2007) ${ }^{7}$ showedthat,theautomotiveproduction'sinterchangenearmodularityandsegmentalsupplyma ycentral to jeopardydivision, chargediscounts, augmentedrapidityofcirculation,andsuperiorelasticity.

2.8. Avittathur and Swamidass, (2007) $)^{\mathbf{8}}$ stated that, there is a clear tendency near sturdier association with sellers in the supply web to progress the presentation of the obtaining corporation.

2.9. Wortham, (2007) ${ }^{9} \quad$ opined

themajorsegmentalgatheringinHyundaiplantsisthebattleground,complete by theHyundai-owned segmentsellerHyundaiMobis, whichpermitstheaccuratebattlegroundtobedistributedtothe accurate welling at the accurate period and with the correct equal of excellence.

2.10. Gould, $(2001)^{10}$ opined that, General Motorsh as roughly30,000sellers, with roughly9,000associatesinits supply chain. It is firm to cooperate with this enormous amount of suppliers and simultaneously exploit the enormous competitive potential advantages of put on modularity in the supply web organization.

\section{Research Methodology:-}

Sources of Data: The strength of any research reliant on the organized mode of information's gathering bases and its exploration. The study is equipped grounded on primary information's and secondary information's. As demanded by the corporations, to uphold the privacy of evidence, the fore names of corporations are not exposed in this research paper. The primary data has collected through oral interview from stalwarts of automotive industry. The secondary data has collected from the reports of international conferences of automotive industry and all existing literature has obtained from internet automotive websites, auto business magazines, and e-auto journals.

Exploration of Data: In exploration of data, to display the occurrence or nonappearance of precise features and to associate and compare facts standards or features midst connected matters with numerous joint features or variables, figures have been equipped and figures are influential communiqué tools - it provides text the concentration of readers, and professionally existent great volumes of composite evidence. 


\section{Results And Discussion:}

Figure.1. Total Quantity of auto parts of Commercial and Passenger Vehicles through supply chain in ASEAN

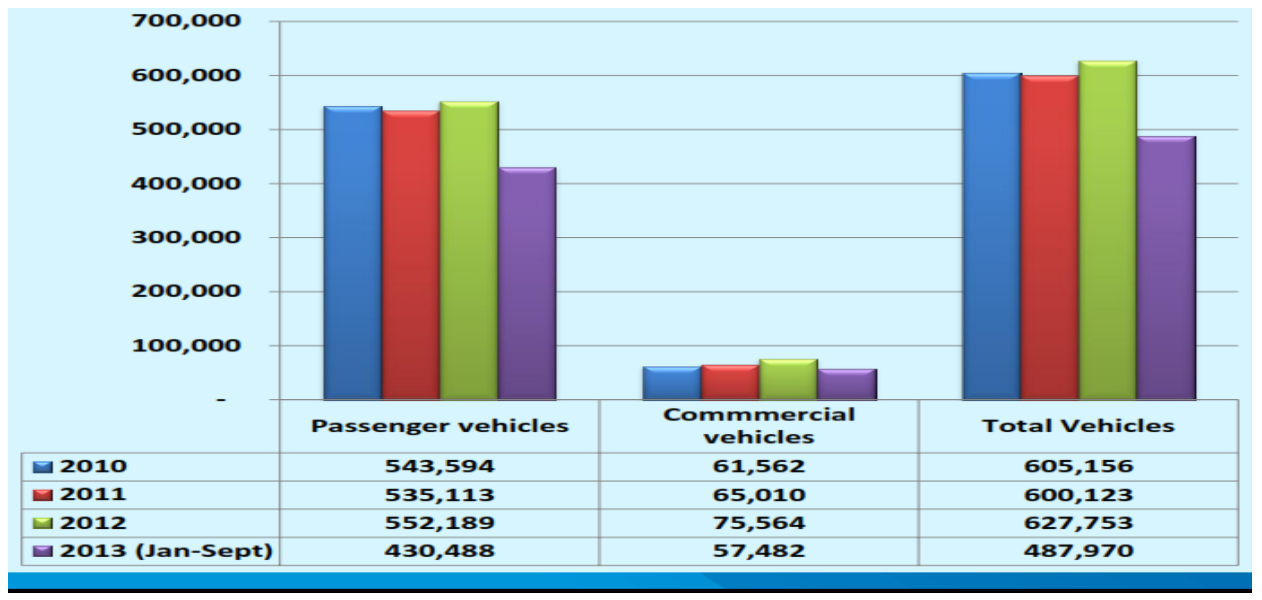

Source: ASEAN Automotive Conference report 2013.

The above figure.1. about the total quantity of auto parts of commercial and passenger vehicles through supply chain in ASEAN. Out of total quantity of vehicles between 2010 to 2013 years. 6, 27,753 is the highest total vehicles consisting of passenger and commercial vehicles in the year 2012 , followed by total vehicles of $4,87,970$ which is the least in the year 2013.

Therefore, it can be concluded that the total quantity of auto parts of commercial and passenger vehicles through supply chain in ASEAN has not improved from 2010 to 2013, but it has decreased due to increasing competition among ASEAN auto parts supply chain management.

Figure.2. Total Import of Completely Built Up (CBU) auto parts through supply chain in ASEAN.

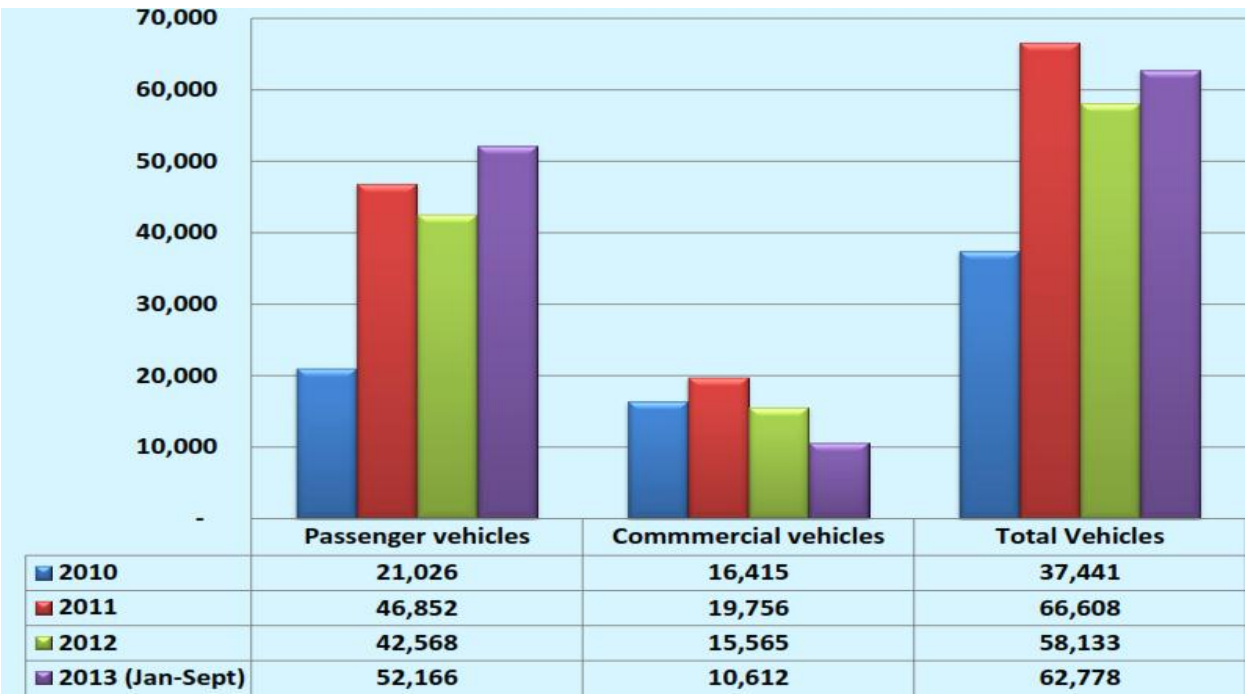

Source: ASEAN Automotive Conference report 2013.

Figure.2. represents about the total import of completely built up (CBU) auto parts through supply chain in ASEAN. Out of total of import of completely built up (CBU) auto parts between 2010 t0 2013, there is increase in total vehicles consisting of passenger and commercial vehicles from 37,441 to 66,608 in the year 2010 to 2011, but it has slightly decreased again in the year 2013 .

Therefore, it can be concluded that the falling tariffs on import of auto parts and components and auto engine also increases rapidly both in absolute terms and equally manufactured vehicle sector contributed to significant downward pressure on prices of auto parts supplier. 


\section{Suggestions:}

1. Finding out the research divulges that, total capacity of auto portions of commercial and passenger vehicles through supply chain in ASEAN has not improved and decreased due to growing competition among ASEAN auto parts supply chain management, in such a case firms of auto parts of ASEAN should worked with suppliers to improve the quality of the materials used, sustainable development, less dependence on gas, rise in green energy enhancement and extraordinary decent customary.

2. Ultimately, despite low tariffs on import of auto parts there is no significant improvement in import, in such a case auto makers mandatory is to team up and syndicate automotive Research and Development influence to protect cash, speed up the overview of new innovative auto technology, grab sturdy controller and progress enterprise with their auto providers to continue the undefined period. Speed up Research and Development in automotive to protect the auto industry, as the innovative auto technology is the significant to protect the auto production.

\section{Conclusion}

Therefore it can be concluded that presently, automotive corporations are involved in a global business evolution. Approximately the whole thing near their trades is fluctuating - their auto goods and amenities, anywhere and in what way they're traded, the amount of administrative contribution, even the essential business simulations of the auto production. At the middle of this immense variation is the automotive supply chain management. For locomotive corporations, developing from this dated of alteration as vigorous, lively trades are subject to outsized amount on how their supply chains familiarize. Better rapidity and competence will help, but won't be enough. Automotive supply chains requirement fact-based aptitude to envisage which forthcoming situations are most likely to transpire - and the elasticity to get transposed previously they do. Now additional than continuously, shrewd successes.

\section{References:}

[1]. Bartlett,P.A.,Julien,D.M.andBaines,T.S.(2007),“Improvingsupplychainperformancethrough improved visibility”,InternationalJournalofLogisticsManagement,Vol.18No.2,pp.294-313.

[2]. Reichhart,A.andHolweg,M.(2007), “Dowestillneedsupplierparks?”,AutomotiveLogistics, March/April, pp.52-8.

[3]. Sandberg, E.(2007),"Logistics collaboration in supply chains :practice vs.theory", International Journal of LogisticsManagement,Vol.18No.2,pp.274-93.

[4]. Kurylko,D.T.(2007),“Audi adopts modular architecture to share parts”,Automotive News, Vol.81No.6255,p.46.

[5]. Erevelles,S.andStevenson,T.H.(2006), "Enhancingthebusiness-to-businesssupplychain:insightsfrompartitioningthesupplyside",IndustrialMarketingManagement,Vol.35 No.4,pp.481-92.

[6]. Doran,D.,Hill,A.,Hwang,K.andJacob,G.(2007),"Supplychainmodularisation:casesfromthe Frenchautomobileindustry",InternationalJournalofProductionEconomics,Vol.106No.1, pp.2-11.

[7]. Kotabe,M.,Parente, R.and Murray, J.Y.(2007),“Antecedents and outcomes of modular productionintheBrazilianautomobileindustry:agroundedtheoryapproach”,Journalof InternationalBusinessStudies,Vol.38No.1,pp.84106.

[8]. Avittathur,B.andSwamidass,P.(2007),“Matchingplantflexibilityandsupplierflexibility: lessonsfromsmallsuppliersofUSmanufacturingplantsinIndia”,JournalofOperations Management,Vol.25No.3,pp.717-35.

[9]. Wortham,A.(2007), “Execsayssuppliersmustdelivermore”,AutomotiveNews,Vol.81No.6256, p.42.

[10]. Gould,L.S.(2001),"Keeping track with symbology”,Automotive Manufacturing \&Production, Vol.113No.3,p.64. 